\title{
Emergency department visits for head trauma in the United States
}

\author{
Christopher E. Gaw ${ }^{1}$ and Mark R. Zonfrillo ${ }^{2^{*}}$
}

\begin{abstract}
Background: Head trauma affects millions of Americans each year and has significant morbidity and economic costs to society. The objective of this study is to describe the epidemiology of head traumas presenting to emergency departments in the United States.

Methods: The National Electronic Injury Surveillance System-All Injury Program was queried to conduct a retrospective analysis of head traumas treated in U.S. emergency departments. 207,159 cases of nonfatal head trauma from January 1, 2007 to December 31, 2011 were included in this study.

Results: An estimated 10,746,629 (95 \% confidence interval: 8,368,720-13,124,537) head traumas were treated in U.S. emergency departments (EDs) during the study period, averaging 2,149,326 cases annually. The annual injury rate per 10,000 population increased from 55.2 in 2007 to 85.4 in 2011, with the largest increases seen in children $\leq 11$ years of age and in adults $>65$ years of age. Traffic-related head trauma accounted for an estimated 1,819,824 visits to U.S. EDs over the study period and was associated with a 1.74 times greater risk of a hospital admission compared to injuries due to non-traffic-related causes. Assaults (95.9\%) were the most common reason for head trauma in cases where injury intent was documented, and $16.9 \%$ of assault-related head trauma occurred in children 0-17 years of age. When analyzed separately from other head traumas, concussions increased by $37.5 \%$ over the study period, and nearly a third (29.9\%) of all concussions were sports-related.
\end{abstract}

Conclusions: The increase in the number and rate of head traumas treated in U.S. EDs warrants continued injury prevention efforts and improvements in injury nomenclature and surveillance.

Keywords: Concussion, Emergency department, Head trauma, National Electronic Injury Surveillance System, Traumatic brain injury

\section{Background}

Head trauma encompasses a wide variety of injuries with differing severities, ranging from trivial head wounds to traumatic brain injuries. In the United States, a large emphasis has been placed on traumatic brain injuries (TBIs); more than 1.7 million TBIs are estimated to occur each year in the U.S., $75 \%$ of which are concussions or other mild traumatic brain injuries $[1,2]$. A diverse array of injury mechanisms have been associated with TBIs, including falls, motor vehicle crashes, assaults, and sports-related injuries [2,3]. Though many patients who suffer a mild TBI recover rapidly and fully, long-term symptoms after injury, including fatigue [4, 5], sleep

\footnotetext{
* Correspondence: Zonfrillo@brown.edu

${ }^{2}$ Department of Emergency Medicine, Alpert Medical School of Brown

University, 55 Claverick St., 2nd floor, Providence, RI 02903, USA

Full list of author information is available at the end of the article
}

disturbances [4], and memory [4, 6], have been well documented. The direct and indirect costs from TBIs to the U.S. economy have been estimated to exceed billions of dollars annually $[7,8]$. Due to the associated high prevalence and costs, TBI prevention has become a public health priority in the United States in recent years $[1,9,10]$.

The epidemiology of head trauma, which encompasses both TBIs as well as more minor head injuries, has not been well represented in the literature. Since patients with head trauma often utilize healthcare resources, understanding head trauma injury patterns is valuable in helping shape public policy and providing information to inform injury prevention efforts. Given that most patients who present with head trauma are often triaged and treated in an emergency department (ED) setting 
[1], a national emergency department dataset, such as the National Electronic Injury Surveillance System (NEISS), is a valuable data source for injury epidemiology studies. The NEISS can be used to generate estimates of injury across U.S emergency departments (EDs), allowing for the characterization of injury patterns and healthcare system burdens on a national level. However, only a few contemporary studies have utilized national emergency department datasets to examine traumatic brain injuries [11] or sports-related concussions [12].

The use of the NEISS in head trauma surveillance was identified in a report to Congress in 2003 by the Centers for Disease Control and Prevention (CDC) as a priority recommendation [1]. Its use, however, has been complicated by the lack of a standardized case definition; the NEISS does not use the International Classification of Diseases, Ninth Revision, Clinical Modification (ICD-9-CM) diagnosis codes in its classification of injury diagnosis $[13,14]$. Recent studies have presented a working case definition for TBIs in the NEISS, which includes concussions, head fractures, and internal organ injuries to the head, that has a high sensitivity and specificity when compared to ICD9-CM diagnosis codes [15-17]. The objective of this study is to describe the epidemiology of head trauma-focusing on secular trends and characteristics of specific modes of injury-treated in U.S. EDs among patients of all ages using the National Electronic Injury Surveillance SystemAll Injury Program (NEISS-AIP).

\section{Methods}

\section{Study design}

This study was a retrospective cohort study utilizing the National Electronic Injury Surveillance System-All Injury Program, a nationally representative database maintained by the U.S. Consumer Product Safety Commission (CPSC). This study was exempt from review by the University of Pennsylvania Institutional Review Board.

\section{Study setting and population}

The NEISS-AIP is a collaborative database maintained jointly by the CDC and the CPSC [18]. Composed of a subset of participating NEISS hospitals, NEISS-AIP monitors all external causes of nonfatal injuries and poisonings treated in U.S. EDs. NEISS-AIP provides data on approximately over 500,000 cases annually and represents a stratified probability sample of all hospitals with a 24-hour ED with at least 6 beds in the United States and its territories $[14,18]$. Professional NEISS coders abstract information from ED medical records including patient demographics, injury diagnosis, affected body region, disposition from the ED, mechanism of injury, and the intent of injury. Through weighting factors provided by the CPSC, NEISS-AIP data can be used to calculate nationally representative estimates of injuries treated nationwide. Data in this study were obtained from the Inter-university Consortium for Political and Social Research, a public data archive maintained by the University of Michigan [19].

All nonfatal head traumas reported through NEISS-AIP from January 1, 2007 to December 31, 2011 were retrospectively analyzed. Cases of head trauma were identified using the following NEISS diagnosis and body part codes in concordance with previous studies [15-17]: concussion (diagnosis code 52), fracture to the head (diagnosis code 57 , body part code 75 ), and internal organ injury to the head (diagnosis code 62 , body part code 75 ). In the event that multiple diagnoses are present in the ED record, the most severe injury is coded. Though previous studies label cases with these diagnosis and body part codes as TBIs, the more conservative term "head trauma" is used throughout this study, as the case definition may include non-TBI injuries in addition to TBIs [16]. A total of 207,159 cases of head trauma during the study period were analyzed. Among these cases, 38,534 cases with a concussion diagnosis (diagnosis code 52) were isolated for sub-analysis.

\section{Study variables}

All study variables were coded by NEISS coders using a standardized data dictionary, and these variables were regrouped for further analysis in this study. The NEISS variable for age was regrouped into 6 age groups: (1) $0-11$, (2) 12-17, (3) 18-24, (4) 25-44, (5) 45-64 and (6) 65+. Disposition from the ED was categorized as (1) treated and released, (2) admitted/hospitalized (including NEISS variables of treated and transferred, treated and admitted, and held for $<24$ hours for observation), (3) left against medical advice, or (4) not documented. The precipitating cause of injury was regrouped into (1) motor vehicle-occupant, (2) motorcyclist, (3) pedal cyclist, (4) pedestrian, (5) other transport, (6) fall, (7) struck by/against, (8) other specified, or (9) unspecified/unknown.

Perpetrator relationship in assault cases were categorized as (1) multiple, (2) friend/acquaintance, (3) spouse/ partner, (4) other relative, (5) stranger, (6) other specified, and (7) unspecified/unknown. The reason for assault was regrouped as (1) altercation, (2) robbery/burglary, (3) other specified, or (4) unspecified/unknown. All analyses involving mechanism of injury utilized the precipitating cause of injury variable (the cause of injury that started the chain of events that leads to an injury) rather than the direct cause of injury, as the precipitating cause is more relevant to injury prevention efforts. The 39 individual sports categories provided by NEISS-AIP were examined, and the top 7 head trauma associated organized sports and the top 12 head trauma associated individual sports were isolated based on prevalence for further analysis. 


\section{Statistical analysis}

Data were analyzed using SPSS version 21.0 (SPSS Inc., Chicago, IL) statistical software. National injury estimates were calculated using statistical weights provided by the CPSC; each sample weight represents the inverse probability of the selection of a logged case. Analyses that involved fewer than 20 unweighted NEISS-AIP cases, 1200 weighted cases, or a coefficient of variation $>30.0 \%$ were considered unstable and were excluded from the results. All data reported in this article are national estimates unless otherwise noted. U.S. Census Bureau intercensal and postcensal population estimates from 2007 to 2011 were used to calculate injury rates for the study period [20-22]. Statistical analyses included Rao-Scott $\chi^{2}$ analysis to assess differences between years for secular trends and calculation of relative risk (RR) with $95 \%$ confidence intervals (CIs).

\section{Results}

\section{Sample demographics}

Between 2007 and 2011, an estimated 10,746,629 (95 \% CI: 8,368,720-13,124,537) patients were treated for head trauma in United States EDs, averaging 2,149,326 (95 \% CI: 1,673,744-2,624,907) or 70.1 (95 \% CI: 54.6-85.6) injuries per 10,000 population annually. Nearly a quarter $(23.3 \%)$ of head traumas was documented in children $\leq 11$ years of age, and males (54.6\%) were injured more often than females (Table 1). Of the $15.7 \%$ of head traumas that resulted in a hospitalization, over a third involved individuals over the age of 65 (35.5\%).

\section{Secular trends}

The annual number of head traumas diagnosed increased by $60.0 \%\left(\chi^{2}=47.95, p<0.001\right)$ over the study period, from 1,662,593 (95 \% CI: 1,188,275-2,136,910) visits in 2007 to 2,659,942 (95 \% CI: 2,040,447$3,279,437$ ) visits in 2011 (Fig. 1). Similarly, annual injury rates per 10,000 population increased by $54.7 \%$, from 55.2 (95 \% CI: 39.4-70.9) in 2007 to 85.4 (95 \% CI: 65.5105.2) in 2011. The largest increases in head trauma diagnoses were documented in children $\leq 11$ years of age and adults older than 65, with increases from 377,803 (95 \% CI: 273,687-481,920) to 614,321 (95 \% CI: 463,161765,482 ) injuries and 244,830 (95 \% CI: 181,167-307,593) to 470,660 (95\% CI: 332,008-609,311) injuries over the study period, respectively. When analyzed by gender, males experienced an increase from 937,484 (95 \% CI: $650,846-1,224,122)$ in 2007 to $1,420,568$ (95 \% CI: $1,097,769-1,743,336)$ in 2011. Females experienced an increase from 724,932 (95 \% CI: 532,714-917,150) to 1,239,293 (95 \% CI: 936,391-1,542,194) over the study period.

When divided into subcategories (Fig. 2), diagnosed head trauma increased in several areas over the study period. Sports-related head trauma experienced a $54.1 \%$ increase, from 267,051 (95 \% CI: 183,751-350,351) injuries in 2007 to 411,606 (95 \% CI: 303,700-519,511) injuries in 2011. Traffic and assault-related head traumas also increased from 2007 to 2011 by 17.3 and $38.1 \%$, respectively.

\section{Traffic-related head trauma}

An estimated 1,819,824 (95 \% CI: 1,068,129-2,571,519) head trauma visits to U.S. EDs during the study period were documented traffic or motor vehicle crashes on highways and roadways. Nearly a third of traffic-related head traumas (31.2\%) involved 25-44 year-olds, followed by $18-24$ year-olds (23.8 \%). The majority of traffic-related head traumas occurred in males (55.6\%). When occupant status in the vehicle was documented, $42.8 \%$ of traffic-related head traumas involved the driver and $23.9 \%$ involved the passenger. An estimated 444,842 (95 \% CI: 166,460-723,224) hospital admissions were associated with traffic-related head trauma, and explicitly documented traffic-related head traumas were 1.74 times (95 \% CI: $1.45-2.08)$ more likely to lead to a hospital admission compared to other causes.

In cases of traffic-related head trauma where the precipitating cause of injury was documented, $78.0 \%$ of all injuries occurred when the patient was in a motor vehicle (Table 2). A greater proportion of males were involved in motorcycle-related $(9.4 \%)$ and pedal-cyclerelated (11.1 \%) head traumas than females $(2.0$ and $3.4 \%$, respectively). Among children $\leq 11$ years of age with a traffic-related head trauma, pedal-cycle-related and pedestrian-related traffic injuries accounted for 13.4 and $10.6 \%$ of head traumas, respectively. In 18-24-year-olds with a traffic-related head trauma, 5.2 and $4.1 \%$ of head traumas were attributed to pedal-cycle-related and pedestrian-related traffic injuries, respectively.

\section{Sports-related head trauma}

1,714,388 (95 \% CI: 1,260,465-2,168,310) sports-related head traumas were treated in U.S. emergency departments from 2007 to 2011. Nearly two-fifths of all sports-related head traumas (37.9\%) occurred in children $12-17$ years of age, and over three-quarters (78.6 \%) of all sports-related head traumas occurred in patients $\leq 24$ years of age. Males (68.9\%) accounted for the majority of sports-related head traumas. When head traumas were stratified by the most commonly associated individual and organized sports, many have a clear male or female predominance (Table 3). Football and basketball were the two most common organized sports associated with a sports-related head trauma, accounting for 12.8 and $7.7 \%$ of all sports-related head traumas, respectively. Bicycling and playground injuries, accounting for 16.7 and $6.8 \%$ of all sports-related head 
Table 1 Characteristics of head trauma treated in U.S. emergency departments

\begin{tabular}{|c|c|c|c|}
\hline Description & Cases (n) & National estimate $(\%)^{a}$ & $95 \%$ confidence interval \\
\hline \multicolumn{4}{|l|}{ Gender } \\
\hline Male & 116,291 & $5,865,536(54.6)$ & $4,532,344-7,198,727$ \\
\hline Female & 90,850 & $4,880,227(45.4)$ & $3,801,087-5,959,367$ \\
\hline Unknown ${ }^{c}$ & 18 & b & b \\
\hline \multicolumn{4}{|l|}{ Age } \\
\hline $0-11$ & 64,976 & $2,506,502(23.3)$ & $1,891,605-3,121,400$ \\
\hline $12-17$ & 28,749 & $1,284,749(12.0)$ & $1,006,639-1,562,859$ \\
\hline $18-24$ & 22,960 & $1,391,571(12.9)$ & $1,006,590-1,776,552$ \\
\hline $25-44$ & 34,519 & 2,099,395 (19.5) & $1,628,127-2,570,663$ \\
\hline $45-64$ & 27,415 & $1,656,661(15.4)$ & $1,273,498-2,039,825$ \\
\hline $65+$ & 28,453 & $1,803,832(16.8)$ & $1,359,072-2,248,592$ \\
\hline Unknown & 87 & b & b \\
\hline \multicolumn{4}{|l|}{ Location } \\
\hline Home & 59,001 & $3,012,637(28.0)$ & $2,259,680-3,765,595$ \\
\hline School/sports/recreation place & 29,063 & $1,283,775(11.9)$ & $983,083-1,584,468$ \\
\hline Street & 36,816 & 2,018,501 (18.8) & $1,232,527-2,804,475$ \\
\hline Other property & 26,943 & $1,504,002(14.0)$ & $1,145,785-1,862,219$ \\
\hline Farm & 340 & $28,406(0.3)$ & $13,033-43,779$ \\
\hline Unknown & 54,996 & 2,899,307 (27.0) & $1,606,967-4,191,646$ \\
\hline \multicolumn{4}{|l|}{ Disposition } \\
\hline Treated and released & 169,772 & $8,913,111(82.9)$ & $6,964,493-1,0861,729$ \\
\hline Admitted/hospitalized & 34,703 & $1,686,349(15.7)$ & $1,118,291-2,254,406$ \\
\hline AMA & 2626 & $144,948(1.3)$ & $88,526-201,370$ \\
\hline Unknown & 58 & b & b \\
\hline \multicolumn{4}{|l|}{ Traffic-related injury } \\
\hline Yes & 32,997 & $1,819,824(16.9)$ & $1,068,129-2,571,519$ \\
\hline No & 5206 & $297,173(2.8)$ & $191,099-403,247$ \\
\hline Unknown/unspecified & 168,956 & $8,629,631(80.3)$ & $6,817,644-10,441,619$ \\
\hline \multicolumn{4}{|l|}{ Sports-related injury } \\
\hline Yes & $36,2701,714,388$ & $1,714,388(16.0)$ & $1,260,465-2,168,310$ \\
\hline No & 147,916 & 7,770,932 (72.3) & $6,037,623-9,504,241$ \\
\hline Unknown/unspecified & 22,973 & $1,261,309(11.7)$ & $964,750-1,557,868$ \\
\hline
\end{tabular}

${ }^{a}$ Percentages may not total to $100 \%$ due to rounding

${ }^{\mathrm{b}}$ Estimate is potentially unstable since unweighted cases $<20$, national estimate $<1200$ cases, or coefficient of variation $>30.0 \%$. No $\mathrm{Cl}$ is provided

'Unknown cases are included in the total estimates of ED visits in the manuscript text

traumas, respectively, were the most common individual sports associated with sports-related head trauma.

Explicitly documented sports-related head traumas were associated with a 0.60 times (95\% CI: 0.51-0.71) risk of hospitalization compared to other causes. An estimated 24,978 patients (95 \% CI: 15,187-34,138), or $4.0 \%$ of all patients who participated in a top 7 organized sport, were hospitalized while $95.3 \%$ were treated and released. In contrast, 127,837 (95 \% CI: 56,893$198,783)$ patients (14.5\%) injured while participating in one of the 12 individual sport or recreational activities were admitted to a hospital. Bicycling (37.6 \%), ATV use (22.1\%), and horseback riding (12.3\%) accounted for nearly three quarters of all individual sports-related hospital admissions.

\section{Head traumas associated with specific intents}

Among cases where intent of injury was documented, assaults were the most common reason associated with head traumas (95.9\%), followed by legal intervention 


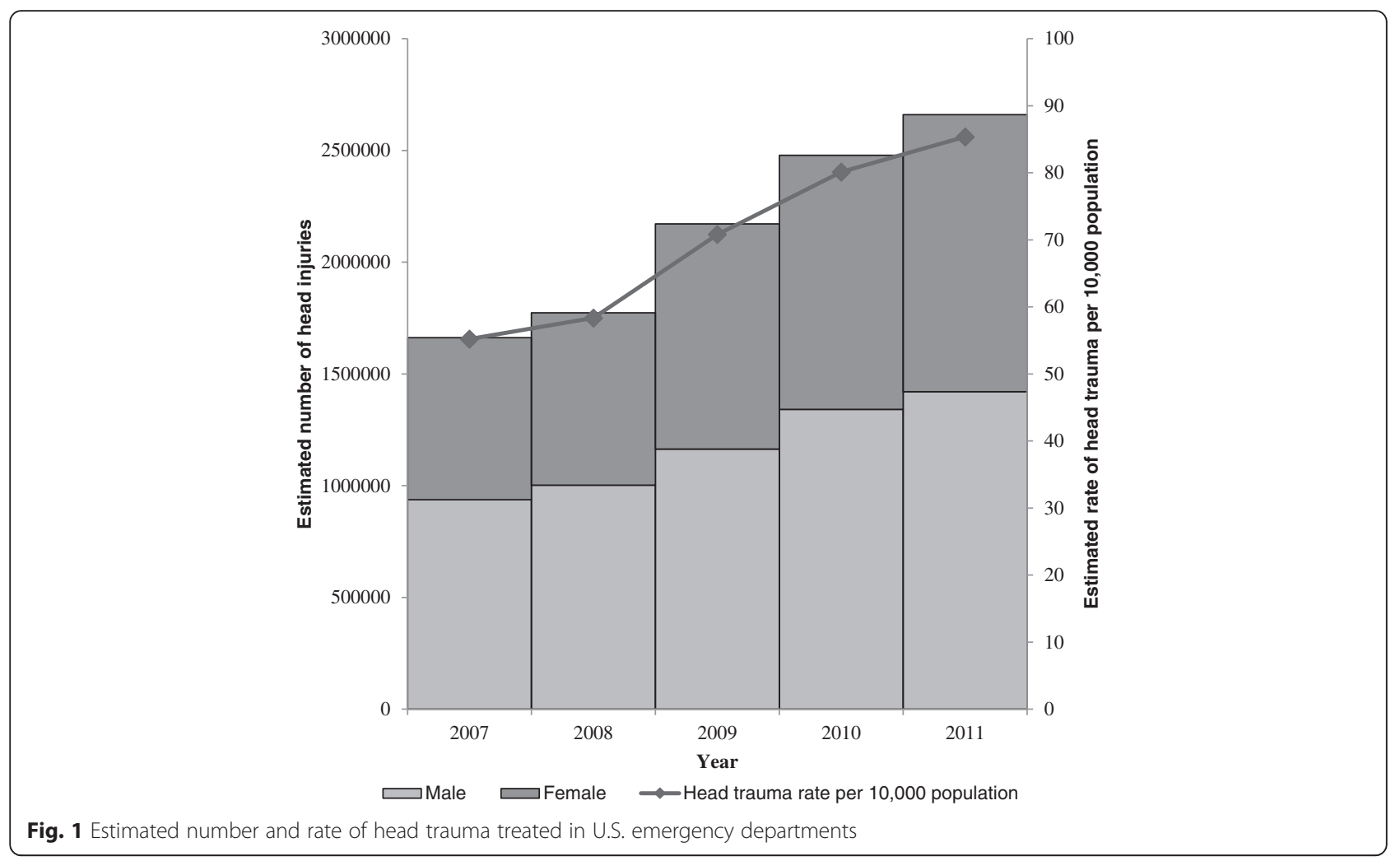

(1.1\%) (Table 4). Multiple perpetrators (38.0 \%) were the most common relationship type documented in head trauma assaults, followed by an acquaintance or friend $(21.6 \%)$. Altercations (81.2 \%) and robberies (12.7\%) were the most commonly cited reason for an assaultrelated head trauma. Nearly two-fifths of all assaultrelated head traumas occurred in the 25-44 year age group (38.8\%), and two-thirds of assault victims were male (66.6 \%). Children less than 18 years of age accounted for $16.9 \%$ of assault-related head traumas. Head traumas associated with legal interventions were most common among patients $25-44$ years of age (48.1\%) and among male patients (89.7\%). Patients who suffered a head trauma related to a self-inflicted injury were nearly 17 times as likely ( $R R=16.77,95 \% \mathrm{CI}$ : 9.90-28.39) to be admitted to a hospital compared to other intents of injury.

\section{Concussions}

An estimated 2,006,477 (95 \% CI: 1,592,183-2,420,772) concussions occurred over the study period, averaging 401,295 (95 \% CI: 318,437-484,154) concussions or 13.1 (95 \% CI: 10.4-15.8) concussions per 10,000 population annually. The number of concussions increased from 344,001 (95 \% CI: 249,465-438,538) in 2007 to 472,881 (95 \% CI: 367,456-578,305) in 2011, an increase of $37.5 \%\left(\chi^{2}=18.21, p=0.001\right)$. The majority of the

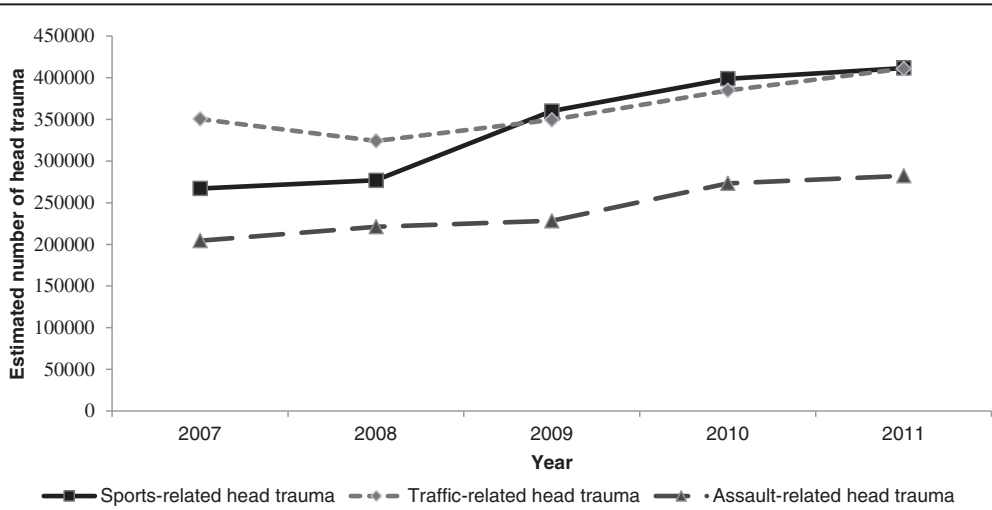

Fig. 2 Estimated number of head trauma treated in U.S. emergency departments by injury precipitant 
Table 2 Estimated number of head trauma treated in U.S. EDs incurred during traffic-related injuries with $95 \% \mathrm{Cl}$

\begin{tabular}{|c|c|c|c|c|c|c|c|c|c|c|}
\hline \multirow{3}{*}{$\frac{\text { Sex }}{\text { Male }}$} & \multicolumn{8}{|c|}{ Precipitating cause of injury (PCI) } & \multirow{2}{*}{\multicolumn{2}{|c|}{ Other transport }} \\
\hline & \multicolumn{2}{|r|}{ MV-occupant } & \multicolumn{2}{|r|}{ Motorcyclist } & \multicolumn{2}{|c|}{ Pedal cyclist } & \multicolumn{2}{|c|}{ Pedestrian } & & \\
\hline & $\begin{array}{l}\text { Estimated } \\
\text { ED visits }\end{array}$ & $\begin{array}{l}\% \text { of all MV-occupant } \\
(95 \% \mathrm{Cl})\end{array}$ & $\begin{array}{l}\text { Estimated } \\
\text { ED visits }\end{array}$ & $\begin{array}{l}\% \text { of all motorcyclist } \\
(95 \% \mathrm{Cl})\end{array}$ & $\begin{array}{l}\text { Estimated } \\
\text { ED visits }\end{array}$ & $\begin{array}{l}\% \text { of all pedal } \\
\text { cyclist }(95 \% \mathrm{Cl})\end{array}$ & Estimated ED visits & $\begin{array}{l}\% \text { of all pedestrian } \\
(95 \% \mathrm{Cl})\end{array}$ & Estimated ED visits & $\begin{array}{l}\% \text { of all other } \\
\text { transport }(95 \% \mathrm{Cl})\end{array}$ \\
\hline $0-11$ & 51,387 & $3.6(3.0-4.2)$ & a & a & 13,565 & $9.7(7.3-12.2)$ & 9740 & $8.6(6.2-11.0)$ & 2476 & $6.8(4.4-9.3)$ \\
\hline $12-17$ & 69,985 & $4.9(4.3-5.6)$ & 3,760 & $3.4(2.3-4.4)$ & 21,672 & $15.5(10.0-21.1)$ & 8943 & $7.9(6.7-9.1)$ & 3975 & $11.0(8.1-13.9)$ \\
\hline $18-24$ & 188,740 & $13.3(12.1-14.5)$ & 20,160 & $18.0(15.7-20.4)$ & 17,415 & $12.5(9.0-16.0)$ & 10,819 & $9.5(8.1-11.0)$ & 2741 & $7.6(5.0-10.2)$ \\
\hline $25-44$ & 233,474 & $16.5(15.4-17.5)$ & 36,201 & $32.4(29.8-35.0)$ & 26,270 & $18.8(16.9-20.8)$ & 18,420 & $16.2(14.5-18.0)$ & 4840 & $13.4(10.4-16.3)$ \\
\hline $45-64$ & 123,525 & $8.7(8.2-9.2)$ & 29,233 & $26.2(22.9-29.4)$ & 25,797 & $18.5(15.9-21.1)$ & 15,590 & $13.7(10.8-16.7)$ & 3566 & $9.9(6.7-13.1)$ \\
\hline \multirow[t]{2}{*}{$65+$} & 47,796 & $3.4(3.0-3.7)$ & 4,588 & $4.1(3.0-5.2)$ & 7818 & $5.6(3.7-7.5)$ & 4971 & $4.4(3.4-5.4)$ & 2424 & $6.7(4.5-8.9)$ \\
\hline & 714,907 & & 95,052 & & 112,537 & & 68,483 & & 20,022 & \\
\hline \multirow[t]{2}{*}{ Female } & \multicolumn{2}{|r|}{ MV-occupant } & \multicolumn{2}{|r|}{ Motorcyclist } & \multicolumn{2}{|c|}{ Pedal cyclist } & \multicolumn{2}{|c|}{ Pedestrian } & \multicolumn{2}{|c|}{ Other transport } \\
\hline & $\begin{array}{l}\text { Estimated } \\
\text { ED visits }\end{array}$ & $\begin{array}{l}\% \text { of all MV-occupant } \\
(95 \% \mathrm{Cl})\end{array}$ & $\begin{array}{l}\text { Estimated } \\
\text { ED visits }\end{array}$ & $\begin{array}{l}\% \text { of all motorcyclist } \\
(95 \% \mathrm{Cl})\end{array}$ & $\begin{array}{l}\text { Estimated } \\
\text { ED visits }\end{array}$ & $\begin{array}{l}\% \text { of all pedal } \\
\text { cyclist }(95 \% \text { Cl) }\end{array}$ & Estimated ED visits & $\begin{array}{l}\% \text { of all pedestrian } \\
(95 \% \mathrm{Cl})\end{array}$ & Estimated ED visits & $\begin{array}{l}\% \text { of all other } \\
\text { transport }(95 \% \mathrm{Cl})\end{array}$ \\
\hline $0-11$ & 44,986 & $3.2(2.7-3.6)$ & a & a & 4351 & $3.1(1.7-4.6)$ & 4482 & $3.9(3.2-4.7)$ & 1322 & $3.7(1.9-5.4)$ \\
\hline $12-17$ & 81,698 & $5.8(5.1-6.4)$ & a & a & 3301 & $2.4(1.4-3.3)$ & 5403 & $4.8(3.7-5.8)$ & 2115 & $5.8(3.5-8.2)$ \\
\hline $18-24$ & 176,821 & $12.5(11.6-13.3)$ & 2,599 & $2.3(1.8-2.9)$ & 5051 & $3.6(1.8-5.5)$ & 6762 & $6.0(5.0-6.9)$ & 2099 & $5.8(4.3-7.3)$ \\
\hline $25-44$ & 218,453 & $15.4(14.3-16.5)$ & 6,639 & $5.9(4.3-7.6)$ & 7482 & $5.4(3.4-7.3)$ & 11,638 & $10.2(8.2-12.3)$ & 3686 & $10.2(7.7-12.7)$ \\
\hline $45-64$ & 130,058 & $9.2(8.3-10.0)$ & 5,766 & $5.2(4.1-6.3)$ & 5228 & $3.7(2.2-5.3)$ & 10,509 & $9.3(7.5-11.0)$ & 3927 & $10.9(8.6-13.1)$ \\
\hline \multirow[t]{2}{*}{$65+$} & 50,281 & $3.5(3.1-3.9)$ & a & a & 1636 & $1.2(0.5-1.8)$ & 5763 & $5.1(3.7-6.4)$ & 2979 & $8.2(5.8-10.7)$ \\
\hline & 702,297 & & 16,396 & & 27,049 & & 44,557 & & 16,128 & \\
\hline
\end{tabular}


Table 3 Organized and individual sports-related head trauma by sex treated in U.S. EDs with $95 \% \mathrm{Cl}$

\begin{tabular}{|c|c|c|c|c|}
\hline \multirow[t]{2}{*}{ Organized sports (OS) } & \multicolumn{2}{|c|}{ Male } & \multicolumn{2}{|c|}{ Female } \\
\hline & Estimated ED visits & $\%$ of all OS (95 \% Cl) & Estimated ED visits & $\%$ of all OS $(95 \% \mathrm{Cl})$ \\
\hline Football & 209,946 & $33.3(30.7-35.8)$ & 10,312 & $1.6(1.3-1.9)$ \\
\hline Basketball & 89,595 & $14.2(12.5-15.9)$ & 42,335 & $6.7(5.8-7.7)$ \\
\hline Soccer & 54,899 & $8.7(7.0-10.4)$ & 43,811 & $6.9(5.3-8.5)$ \\
\hline Baseball & 68,416 & $10.8(9.6-12.0)$ & 15,106 & $2.4(1.9-2.9)$ \\
\hline Hockey & 34,109 & a & 7341 & $1.2(0.6-1.7)$ \\
\hline Softball & 12,304 & $2.0(1.5-2.4)$ & 28,912 & $4.6(3.9-5.2)$ \\
\hline Volleyball & 3081 & $0.5(0.2-0.7)$ & 10,767 & $1.7(1.4-2.1)$ \\
\hline \multirow[t]{2}{*}{ Individual sports (IS) } & \multicolumn{2}{|c|}{ Male } & \multicolumn{2}{|c|}{ Female } \\
\hline & Estimated ED visits & $\%$ of all IS (95\% Cl) & Estimated ED visits & $\%$ of all IS (95\% CI) \\
\hline Bicycle & 221,150 & $25.1(22.7-27.5)$ & 65,828 & $7.5(6.6-8.4)$ \\
\hline Playground & 63,921 & $7.3(5.8-8.7)$ & 52,023 & $5.9(4.8-7.0)$ \\
\hline ATV & 56,149 & $6.4(4.0-8.8)$ & 24,542 & $2.8(1.5-4.0)$ \\
\hline Horseback & 16,376 & $1.9(0.9-2.8)$ & 45,481 & $5.2(3.9-6.5)$ \\
\hline Skateboard & 43,506 & $4.9(3.3-6.5)$ & 6186 & $0.7(0.4-1.0)$ \\
\hline Snow skiing & 32,643 & a & 14,649 & a \\
\hline Misc ball games & 31,143 & $3.5(2.4-4.7)$ & 13,963 & $1.6(0.9-2.2)$ \\
\hline Exercise & 24,628 & $2.8(2.3-3.3)$ & 20,253 & $2.3(1.9-2.7)$ \\
\hline Swimming & 26,392 & $3.0(2.6-3.4)$ & 18,423 & $2.1(1.7-2.5)$ \\
\hline Moped/Minibike/Other Off-road & 35,314 & $4.0(3.2-4.8)$ & 4421 & $0.5(0.3-0.7)$ \\
\hline Gymnastics & 5,627 & $0.6(0.4-0.8)$ & 27,638 & $3.1(2.5-3.8)$ \\
\hline Combative & 26,269 & $3.3(2.5-4.1)$ & 1811 & $0.2(0.1-0.3)$ \\
\hline
\end{tabular}

${ }^{a}$ Estimate is potentially unstable since unweighted cases $<20$, national estimate $<1200$ cases, or coefficient of variation $>30.0 \%$. No $\mathrm{Cl}$ is provided

increase in concussions was attributed to sports-related injuries (Fig. 3). Concussions were documented most often in males (57.9 \%). Two-fifths of all concussions occurred in patients $12-24$ years of age $(40.0 \%)$. Sportsrelated injuries accounted for $29.9 \%$ of all concussions, and football-related concussions accounted for nearly a fifth (19.4 \%) of all sports-related concussions. Children less than 18 years of age accounted for $19.4 \%$ of assaultrelated concussions.

\section{Discussion}

Between 2007 and 2011, the number of diagnosed head traumas in U.S. EDs increased by $60 \%$; subgroup analyses noted that a substantial proportion of the increase was concentrated in children under the age of 11 and in adults over the age of 65 . The increases in diagnosed head trauma may be explained partially by a combination of increased awareness by the public and increased diagnosis by healthcare practitioners $[1,10,11,23]$. Providers may be more aware of the potential dangers of head trauma, thus increasing reporting. Similarly, parents and caretakers may be more aware of potential injuries to the children and elderly after sustaining a hit to the head from an object or a fall, thus leading to more patients presenting for evaluation. Alternatively, Marin and colleagues have postulated that increases in TBIs among young children and the elderly may be associated with these cohorts receiving fewer benefits from public health efforts, many of which focus on teenagers through middle-aged adults, specifically through legislation protecting student athletes and through motor vehicle laws [11].

The proportion of explicitly documented traffic-related injuries comprised nearly one-fifth (17\%) of all head traumas. This figure was in concordance with previously published studies, with another large nationally representative database study documenting motor vehicle traffic accidents as a mechanism of injury in approximately $16 \%$ of TBIs in its sample in 2010 [11]. Moreover, traffic-related diagnosed head trauma increased by $17 \%$ over the study period. Previous studies have documented a decline in traffic-related TBI hospitalizations in adolescents and other cohorts over time, and 
Table 4 Characteristics of head trauma associated with specific intents treated in U.S. EDs

\begin{tabular}{llrr}
\hline Description & Cases (n) & \multicolumn{1}{l}{$\begin{array}{l}\text { National } \\
\text { estimate (\%) }\end{array}$} & \multicolumn{1}{l}{$\begin{array}{l}\text { 95 \% confidence } \\
\text { interval }\end{array}$} \\
\hline Intent & & & \\
Assault & 22,010 & $1,209,403(95.9)$ & $923,354-1,495,451$ \\
Legal intervention & 722 & $38,238(1.1)$ & $27,960-48,517$ \\
$\begin{array}{l}\text { Self-harm } \\
\text { Perpetrator relationship }\end{array}$ & 241 & $13,668(3.0)$ & $7,513-19,823$ \\
in assault & & & \\
Multiple & 4421 & $230,032(38.0)$ & $158,331-301,733$ \\
Friend/acquaintance & 2520 & $130,650(21.6)$ & $100,598-160,702$ \\
Spouse/partner & 2130 & $127,958(21.1)$ & $95,647-160,269$ \\
Other relative & 911 & $48,894(8.1)$ & $37,968-59,819$ \\
Stranger & 804 & $44,933(7.4)$ & $26,666-63,199$ \\
Other specified & 531 & $23,771(3.9)$ & $17,800-29,742$ \\
Reason for assault & & & \\
Altercation & 4193 & $225,363(81.2)$ & $176,632-274,095$ \\
Robbery/burglary & 653 & $35,251(12.7)$ & $21,057-49,445$ \\
Other specified & 394 & $16,928(6.1)$ & $7,685-26,172$ \\
\hline
\end{tabular}

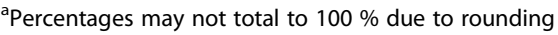

improvements to vehicle and traffic safety have been cited as a reasons for this decline [24, 25]. The decline in hospitalizations may signal a decrease in the severity of head traumas sustained in traffic-related crashes and demonstrate the positive impact of long-term public health efforts. However, this observation is tempered by the observed increase in traffic-related head traumas noted in this study. Although the cause for this increase is ultimately unknown, increased diagnosis by providers and awareness by the public may be contributing factors. Injury prevention efforts should continue to focus on atrisk groups, such as adolescent and young drivers.
Nearly a fifth of both assault-related head traumas (17\%) and assault-related concussions (19\%) occurred in children $<18$ years of age. These proportions suggest that a number of children may be presenting to U.S. EDs with assault-related head traumas, some of which are clinically mild. The mechanisms of assault-related injury are diverse and include blows to the head or other body parts, dropping, throwing, or shaking [26]. Most of the literature has generally focused on the characterization of moderate and severe TBI [27-30]. Mild TBIs, however, may also occur in assault injuries that do not directly involve the head, and it is likely that these injuries are underdiagnosed. Given the potential morbidity from untreated mild head trauma [4, 5, 31], healthcare providers should be vigilant for head traumas that may be secondary to other injuries in assault cases. An emphasis should be placed on ED and first responder education to detect cases of potential abuse and to evaluate for head trauma in such cases.

Nearly a third (30\%) of concussions was associated with a sport or recreational activity. Clear guidelines currently exist with respect to sports concussion management and opportunities for injury prevention exist through rule and culture changes in many sports [32]. Despite recent publicity and increased awareness, misconceptions regarding concussion symptoms and acceptable return to play guidelines persist among patients, coaches, and physicians [33-36]. On the field or court, rule enforcement and player protection are inconsistent, and unadvised play is still undertaken in light of athletic or peer pressure. A recently rejected settlement in a class action lawsuit against the National Collegiate Athletic Association (NCAA) highlights this issue and negotiations to overhaul NCAA concussion management policies are continuing [37, 38]. Sustained educational efforts and improved rule enforcement remain critical in protecting athlete health.

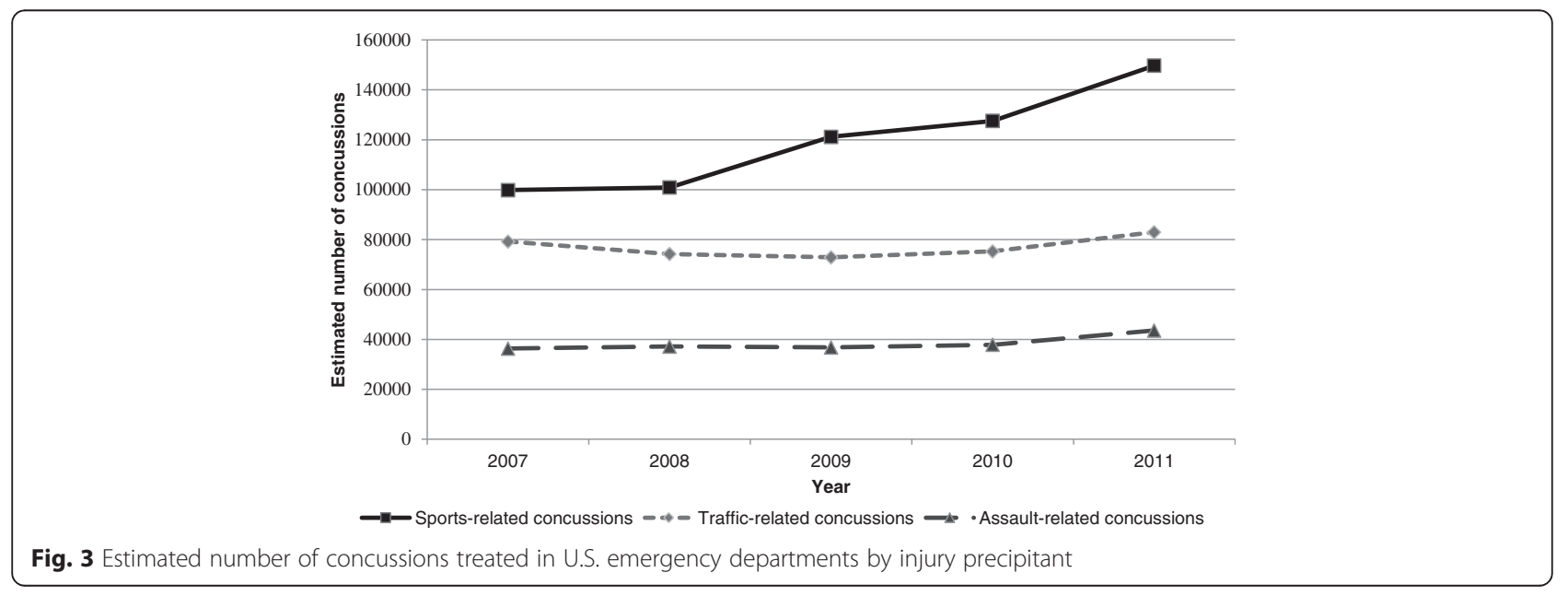


As the NEISS is designed specifically for injury surveillance purposes $[13,14]$, it provides information on injury mechanism, injury intent, and data on sports and recreational-related injuries not available in other administrative databases. However, the NEISS is difficult to compare to these databases due to the use of its own diagnostic coding system rather than ICD-9-CM codes $[13,18]$. Rather than attempting to overhaul the NEISS, most efforts have focused on improving the accuracy and sensitivity of head trauma studies via epidemiological means. Studies by Xiang et al. and Thompson et al. sought to validate a proposed TBI case definition, utilizing the CDC ICD-9-CM TBI definition as a gold standard [15-17]. The sensitivity of TBI identification in these studies were high, however, a proportion of cases were not captured as TBIs in the NEISS $[15,16,39,40]$. Thus, the term head trauma is used during the application of the case definition in this study, as this term is a more conservative and accurate descriptor of the cases captured by the proposed NEISS case definition.

This study has several limitations. Injuries treated in urgent care centers, physician offices, or on athletic fields that do not present to an emergency department are not captured by the NEISS database. The number of head traumas is likely to be underestimated, particularly minor head traumas, of which a substantial portion are treated in an outpatient setting [41]. Therefore, the results presented here may not be representative of all head traumas in the United States. The NEISS coding guidelines for coding internal organ injuries to the head is relatively nonspecific and may include cases where no explicit diagnosis of head trauma was made [18]. Furthermore, the NEISS database only includes the most severe diagnosis for each case, even if multiple diagnoses are present in ED records. Cases may have been excluded from this study when head trauma was, in fact, present [16]. The use of ICD-9-CM as a gold standard for validating the NEISS case definition used is also a limitation, as ICD-9-CM codes have long been criticized as a flawed means of disease classification, especially in cases of traumatic brain injury [40, 42, 43]. Development and assessment of a new bridging matrix between the NEISS and the ICD-10-CM coding system may be beneficial in developing a better working case definition for head injuries, as previous efforts with ICD-9-CM codes demonstrated promising results [17]. Despite these limitations, the strength of this study lies in its large, nationally representative sample and the concordance of its results with other studies utilizing large administrative datasets $[11,12]$.

\section{Conclusions}

In summary, the increase in the number and rate of diagnosed head traumas treated in U.S. EDs warrants continued injury prevention efforts and public awareness. Currently, major injury prevention efforts have focused on improving motor vehicle safety and safe play in sports. The focus of these interventions targets a large proportion of the population, but also is less likely to include younger children and the elderly. As the public and medical community become more aware of the potential dangers of head traumas, regardless of severity, expanding injury prevention efforts to include these populations will become increasingly important, and may involve provider awareness concerning head trauma in child abuse, safe play for younger children, and product and home safety.

\section{Abbreviations \\ CDC: Centers for Disease Control and Prevention; Cl: confidence interval; CPSC: U.S. Consumer Product Safety Commission; ED: emergency department; ICD-9-CM: International Classification of Diseases, Ninth Revision, Clinical Modification; NCAA: National Collegiate Athletic Association; NEISS: National Electronic Injury Surveillance System; NEISS-AIP: NEISS-All Injury Program; RR: relative risk; TBI: traumatic brain injury.}

\section{Competing interests}

The authors declare that they have no competing interests.

\section{Authors' contributions}

CEG participated in the conceptualization of the study, conducted the data analyses, interpreted the results, wrote the manuscript, and approved the final manuscript. MRZ conceptualized and supervised all aspects of the study, assisted in data analysis, interpreted results, critically reviewed and revised the manuscript, and approved the final manuscript.

\section{Acknowledgements}

The authors would like to acknowledge Kristina Metzger, PhD, MPH for her assistance with the statistical analysis performed in this study. This study was supported by the National Institutes of Health, Eunice Kennedy Shriver

National Institute of Child Health and Human Development, grant K08HD073241, awarded to author MZ. The opinions, findings, and conclusions expressed in this publication are those of the authors and do not necessarily reflect the views of the National Institutes of Health.

\section{Author details}

${ }^{1}$ Perelman School of Medicine at the University of Pennsylvania, 3400 Civic Center Boulevard, Building 421, Philadelphia, PA 19104, USA. ${ }^{2}$ Department of Emergency Medicine, Alpert Medical School of Brown University, 55 Claverick St., 2nd floor, Providence, RI 02903, USA.

Received: 20 October 2015 Accepted: 7 January 2016

Published online: 19 January 2016

\section{References}

1. National Center for Injury Prevention and Control. Report to congress on mild traumatic brain injury in the United States: steps to prevent a serious public health problem. Atlanta: Centers for Disease Control and Prevention; 2003.

2. Faul M, Xu L, Wald MM, Coronado VG. Traumatic brain injury in the United States: emergency department visits, hospitalizations, and deaths 2002-2006. Atlanta: Centers for Disease Control and Prevention, National Center for Injury Prevention and Control; 2010.

3. Bazarian JJ, McClung J, Shah MN, Cheng YT, Flesher W, Kraus J. Mild traumatic brain injury in the United States, 1998-2000. Brain Inj. 2005;19:85-91.

4. Kraus J, Hsu P, Schaffer K, Vaca F, Ayers K, Kennedy F, et al. Preinjury factors and 3-month outcomes following emergency department diagnosis of mild traumatic brain injury. J Head Trauma Rehabil. 2009;24:344-54.

5. Norrie J, Heitger M, Leathem J, Anderson T, Jones R, Flett R. Mild traumatic brain injury and fatigue: a prospective longitudinal study. Brain Inj. 2010;24:1528-38. 
6. Ponsford J, Cameron P, Fitzgerald M, Grant M, Mikocka-Walus A. Long-term outcomes after uncomplicated mild traumatic brain injury: a comparison with trauma controls. J Neurotrauma. 2011;28:937-46.

7. Coronado VG, McGuire LC, Sarmiento K, Bell J, Lionbarger MR, Jones CD, et al. Trends in traumatic brain injury in the U.S. and the public health response: 1995-2009. J Safety Res. 2012:43:299-307.

8. Finklestein E, Corso PS, Miller TR. The incidence and economic burdens of injuries in the United States. New York: Oxford University Press; 2006.

9. Wiebe DJ, Comstock RD, Nance ML. Concussion research: a public health priority. Inj Prev. 2011;17:69-70.

10. Underwood E. NFL kicks off brain injury research effort. Science. 2013;339:1367.

11. Marin JR, Weaver MD, Yealy DM, Mannix RC. Trends in visits for traumatic brain injury to emergency departments in the United States. JAMA. 2014;311:1917-9.

12. Bakhos LL, Lockhart GR, Myers R, Linakis JG. Emergency department visits for concussion in young child athletes. Pediatrics. 2010;126:e550-6.

13. NEISS. The national electronic injury surveillance system, a tool for researchers. Washington, D.C.: U.S. Consumer Product Safety Commission; 2000.

14. Schroeder T. The NEISS sample (design and implementation) 1997 to Present. Washington, D.C.: U.S. Consumer Product Safety Commission; 2001.

15. Xiang $H$, Sinclair SA, Yu S, Smith GA, Kelleher K. Case ascertainment in pediatric traumatic brain injury: challenges in using the NEISS. Brain Inj. 2007;21:293-9

16. Thompson MC, Wheeler KK, Shi J, Smith GA, Groner Jl, Haley KJ, et al. Surveillance of paediatric traumatic brain injuries using the NEISS: choosing an appropriate case definition. Brain Inj. 2014;28:431-7.

17. Thompson MC, Wheeler KK, Shi J, Smith GA, Xiang H. An evaluation of comparability between NEISS and ICD-9-CM injury coding. PLoS One. 2014;9, e92052.

18. U.S. Department of Health and Human Services, Centers for Disease Control and Prevention, National Center for Injury Prevention and Control, U.S. Consumer Product Safety Commission. National Electronic Injury Surveillance System All Injury Program, 2011. Atlanta: 2011.

19. Inter-university Consortium for Political and Social Research. National Electronic Injury Surveillance System (NEISS) Series 2014.

20. U.S. Census Bureau. US-EST90INT-07: intercensal estimates of the United States resident population by age and sex, 1990-2000: selected months. 2004.

21. U.S. Census Bureau. US-ESTOOINT-ALLDATA: intercensal estimates of the resident population by single year of age, sex, race and hispanic origin for the United States: April 1, 2000 to July 1, 2010. 2011

22. U.S. Census Bureau. NC-EST2011-ALLDATA: monthly population estimates by age, sex, race, and Hispanic origin for the United States: April 1, 2010 to July 1, 2011 (with short-term projections to dates in 2012). 2012.

23. Covassin T, Elbin RJ, Sarmiento K. Educating coaches about concussion in sports: evaluation of the CDC's "Heads Up: concussion in youth sports" initiative. J Sch Health. 2012;82:233-8.

24. Asemota AO, George BP, Bowman SM, Haider AH, Schneider EB. Causes and trends in traumatic brain injury for United States adolescents. J Neurotrauma. 2013:30:67-75.

25. Thurman D, Guerrero J. Trends in hospitalization associated with traumatic brain injury. JAMA. 1999;282:954-7.

26. Hahn YS, Raimondi AJ, McLone DG, Yamanouchi Y. Traumatic mechanisms of head injury in child abuse. Childs Brain. 1983;10:229-41.

27. Eisele JA, Kegler SR, Trent RB, Coronado VG. Nonfatal traumatic brain injury - related hospitalization. J Head Trauma Rehabil. 2006:21:537-43.

28. Irie F, Le Brocque R, Kenardy J, Bellamy N, Tetsworth K, Pollard C. Epidemiology of traumatic epidural hematoma in young age. J Trauma. 2011;71:847-53.

29. Finkelhor D, Ormrod R, Turner H, Hamby SL. The victimization of children and youth: a comprehensive, national survey. Child Maltreat. 2005;10:5-25.

30. Fazel S, Wolf A, Pillas D, Lichtenstein P, Långström N. Suicide, fatal injuries, and other causes of premature mortality in patients with traumatic brain injury: a 41-year Swedish population study. JAMA Psychiatr. 2014;71:326-33.

31. King NS, Kirwilliam S. Permanent post-concussion symptoms after mild head injury. Brain Inj. 2011;25:462-70.

32. McCrory P, Meeuwisse WH, Aubry M, Cantu B, Dvorák J, Echemendia RJ, et al. Consensus statement on concussion in sport: the 4th International
Conference on Concussion in Sport held in Zurich, November 2012 Am Coll Surg. 2013;216:e55-71.

33. Zonfrillo MR, Master CL, Grady MF, Winston FK, Callahan JM, Arbogast KB. Pediatric providers' self-reported knowledge, practices, and attitudes about concussion. Pediatrics. 2012;130:1120-5.

34. Garrick JG. Unreported concussion in high school football players. Clin J Sport Med. 2005;15:385. author reply 385.

35. McLeod TCV, Schwartz C, Bay RC. Sport-related concussion misunderstandings among youth coaches. Clin J Sport Med. 2007;17:140-2.

36. Stevens PK, Penprase B, Kepros JP, Dunneback J. Parental recognition of postconcussive symptoms in children. J Trauma Nurs. 2010;17:178-82. quiz 183-4

37. Straus B. N.C.A.A. Deal revamps head-injury care. New York Times; 2014

38. Strauss B. Judge rejects $\$ 75$ million settlement in Lawsuit against N.C.A.A. on head injuries. The New York Times. 2014.

39. Hunt JP, Cherr GS, Hunter C, Wright MJ, Wang YZ, Steeb G, et al. Accuracy of administrative data in trauma: splenic injuries as an example. J Trauma. 2000;49:679-86. discussion 686-8.

40. Roozenbeek B, Maas AIR, Menon DK. Changing patterns in the epidemiology of traumatic brain injury. Nat Rev Neurol. 2013;9:231-6.

41. Mannix R, O'Brien MJ, Meehan WP. The epidemiology of outpatient visits for minor head injury: 2005 to 2009. Neurosurgery. 2013;73:129-34. discussion 134.

42. Bazarian JJ, Veazie P, Mookerjee S, Lerner EB. Accuracy of mild traumatic brain injury case ascertainment using ICD-9 codes. Acad Emerg Med. 2006;13:31-8.

43. Carroll CP, Cochran JA, Guse CE, Wang MC. Are we underestimating the burden of traumatic brain injury? Surveillance of severe traumatic brain injury using centers for disease control International classification of disease, ninth revision, clinical modification, traumatic brain injury codes. Neurosurgery. 2012;71:1064-70. discussion 1070.

\section{Submit your next manuscript to BioMed Central and we will help you at every step:}

- We accept pre-submission inquiries

- Our selector tool helps you to find the most relevant journal

- We provide round the clock customer support

- Convenient online submission

- Thorough peer review

- Inclusion in PubMed and all major indexing services

- Maximum visibility for your research

Submit your manuscript at www.biomedcentral.com/submit 